Acta Univ. Sapientiae, Mathematica, 12, 2 (2020) 307-316

DOI: $10.2478 /$ ausm-2020-0022

\title{
On $\lambda^{\mathrm{D}}-\mathrm{R}_{0}$ and $\lambda^{\mathrm{D}}-\mathrm{R}_{1}$ spaces
}

\author{
Sarhad F. Namiq \\ Department of Mathematics, \\ College of Education, \\ University of Garmian, \\ Kurdistan-Region, Iraq \\ email: sarhad1983@gmail.com
}

\author{
Ennis Rosas \\ Departamento de Ciencias \\ Naturales y Exactas, \\ Universidad de la Costa, Barranquilla, \\ Colombia \& Departmento de \\ Matemáticas, Universidad de Oriente, \\ Cumaná, Venezuela \\ email: ennisrafael@gmail.com
}

\begin{abstract}
In this paper we introduce the new types of separation axioms called $\lambda^{\mathrm{D}}-\mathrm{R}_{0}$ and $\lambda^{\mathrm{D}}-\mathrm{R}_{1}$ spaces, by using $\lambda^{\mathrm{D}}$-open set. The notion $\lambda^{\mathrm{D}}-\mathrm{R}_{0}$ and $\lambda^{\mathrm{D}}-\mathrm{R}_{1}$ spaces are introduced and some of their properties are investigated.
\end{abstract}

\section{Introduction}

In 1943, the notion of $R_{0}$ topological space was introduced by Shanin [6]. Later, Davis [3] rediscovered it and studied some properties of this weak separation axiom. In the same paper, Davis also introduced the notion of $R_{1}$ topological space which are independent of both $T_{0}$ and $T_{1}$, but strictly weaker than $T_{2}$. The notion of $\lambda$-open ( $\lambda^{*}$-open) sets was introduced by Alais B. Khalaf and Sarhad F. Namiq [1]. The notion of $\lambda^{\mathrm{D}}$-open sets was introduced by Sarhad F. Namiq [5]. In this paper, we continue the study of the above mentioned classes of topological spaces satisfying these axioms by introducing two more notions in terms of $\lambda^{\mathrm{D}}$-open sets called $\lambda^{\mathrm{D}}-\mathrm{R}_{0}$ and $\lambda^{\mathrm{D}}-\mathrm{R}_{1}$.

2010 Mathematics Subject Classification: 54A05, 54B05, 54C05

Key words and phrases: $\lambda^{\mathrm{D}}-$ open set; $\lambda^{\mathrm{D}}-\mathrm{R}_{0}$ and $\lambda^{\mathrm{D}}-\mathrm{R}_{1}$ 


\section{Preliminaries}

Throughout, $X$ denote a topological space. Let $A$ be a subset of $X$, the closure and the interior of $A$ are denoted by $\mathrm{Cl}(A)$ and $\operatorname{Int}(A)$ respectively. A subset $A$ of a topological space $(X, \tau)$ is said to be dense set [7] if $\mathrm{Cl}(A)=X$. A subset $A$ of a topological space $(X, \tau)$ is said to be semi open [4] if $A \subseteq \operatorname{Cl}(\operatorname{Int}(A))$. The complement of a semi open set is said to be semi closed [4]. The family of all semi open (resp. semi closed) sets in a topological space $(X, \tau)$ is denoted by $\mathrm{SO}(X, \tau)$ or $\mathrm{SO}(X)$ (resp. $\mathrm{SC}(X, \tau)$ or $S C(X)$ ). We consider $\lambda$ as a function defined on $\mathrm{SO}(X)$ into $\mathcal{P}(X)$ and $\lambda: S O(X) \rightarrow \mathcal{P}(X)$ is called an s-operation if $\mathrm{V} \subseteq \lambda(\mathrm{V})$ for each non-empty semi open set $\mathrm{V}$. It is assumed that $\lambda(\emptyset)=\emptyset$ and $\lambda(X)=X$ for any s-operation $\lambda$.

Definition 1 [1] Let $(\mathrm{X}, \tau)$ be a topological space and $\lambda: \mathrm{SO}(\mathrm{X}) \rightarrow \mathcal{P}(\mathrm{X})$ be an s-operation, then a subset $\mathrm{A}$ of $\mathrm{X}$ is called $a \lambda^{*}$-open set which is equivalent to $\lambda$-open set, if for each $\mathrm{x} \in \mathrm{A}$, there exists a semi open set $\mathrm{U}$ such that $\mathrm{x} \in \mathrm{U}$ and $\lambda(\mathrm{U}) \subseteq \mathrm{A}$. The complement of a $\lambda^{*}$-open set is said to be $\lambda^{*}$-closed set which is equivalent to $\lambda$-closed set. The family of all $\lambda^{*}$-open (resp., $\lambda^{*}$-closed) subsets of a topological space $(\mathrm{X}, \tau)$ is denoted by or $\mathrm{SO}_{\lambda}(\mathrm{X})$ (resp. $\mathrm{SC}_{\lambda}(\mathrm{X}, \tau)$ or $\mathrm{SC}_{\lambda}(\mathrm{X})$ ).

Definition 2 [5] Let $(\mathrm{X}, \tau)$ be a topological space and $\lambda: \mathrm{SO}(\mathrm{X}) \rightarrow \mathcal{P}(\mathrm{X})$ be an s-operation, then a $\lambda^{*}$-open subset $\mathrm{A}$ of $\mathrm{X}$ is called a $\lambda^{\mathrm{D}}$-open set, if for each $x \in A$, there exists a dense set $\mathrm{D}$ such that $\mathrm{x} \in \mathrm{D} \subseteq \mathrm{A}$. The complement of a $\lambda^{\mathrm{D}}$-open set is said to be $\lambda^{\mathrm{D}}$-closed. The family of all $\lambda^{\mathrm{D}}$-open (resp., $\lambda^{\mathrm{D}}$-closed) subsets of a topological space $(\mathrm{X}, \tau)$ is denoted by or $\left.\mathrm{SO}_{\lambda \mathrm{D}}\right)(\mathrm{X})$ or $\mathrm{SO}_{\lambda \mathrm{D}}(\mathrm{X}, \tau)$ (resp. $\mathrm{SC}_{\lambda_{\mathrm{D}}}(\mathrm{X}, \tau)$ or $\mathrm{SC}_{\lambda_{\mathrm{D}}}(\mathrm{X})$ ).

Example 1 Let $X=\{a, b, c, d\}$ with topology $\tau=\{\emptyset, X,\{a\},\{b\},\{a, b\},\{a, b, c\}\}$. The $\operatorname{SO}(X)=\{\emptyset, X,\{a\},\{b\},\{a, b\},\{a, c\},\{a, d\},\{b, c\},\{b, d\},\{a, b, c\},\{a, b, d\}$, $\{\mathrm{b}, \mathrm{c}, \mathrm{d}\},\{\mathrm{a}, \mathrm{c}, \mathrm{d}\}\}$. Define $\lambda: \mathrm{SO}(\mathrm{X}) \rightarrow \mathcal{P}(\mathrm{X})$ as:

$$
\lambda(A)= \begin{cases}A & \text { if } a \in A \\ X & \text { if } a \notin A\end{cases}
$$

The $\mathrm{SO}_{\lambda \mathrm{D}}(\mathrm{X})=\{\emptyset, X,\{\mathrm{a}, \mathrm{b}\},\{\mathrm{a}, \mathrm{b}, \mathrm{c}\},\{\mathrm{a}, \mathrm{b}, \mathrm{d}\}\}$.

Definition 3 [5] Let $(\mathrm{X}, \tau)$ be a topological space and let $\mathrm{A}$ be a subset of $\mathrm{X}$. Then:

1. The $\lambda$-closure of $\mathrm{A}$ (denoted by $\lambda^{\mathrm{D}} \mathrm{Cl}(\mathrm{A})$ ) is the intersection of all $\lambda^{\mathrm{D}}-$ closed sets containing $A$. 
2. The $\lambda$-interior of $\mathrm{A}$ (denoted by $\left.\lambda^{\mathrm{D}} \operatorname{Int}(\mathrm{A})\right)$ is the union of all $\lambda^{\mathrm{D}}$-open sets of $\mathrm{X}$ contained in $\mathrm{A}$.

Proposition 1 [5] For each point $x \in X, x \in \lambda^{\mathrm{D}} \mathrm{Cl}(A)$ if and only if $\mathrm{V} \cap A \neq \emptyset$, for every $\mathrm{V} \in \mathrm{SO}_{\lambda^{\mathrm{D}}}(\mathrm{X})$ such that $\mathrm{x} \in \mathrm{V}$.

\section{On $\lambda^{\mathrm{D}}-\mathrm{R}_{0}$ and $\lambda^{\mathrm{D}}-\mathrm{R}_{1}$ spaces}

We introduce the following definitions.

Definition 4 For any s-operation $\lambda: \mathrm{SO}(\mathrm{X}) \rightarrow \mathcal{P}(\mathrm{X})$ and any subset $\mathrm{A}$ of a space $(\mathrm{X}, \tau)$ the $\lambda^{\mathrm{D}}$-kernel of $\mathrm{A}$, denoted by $\lambda^{\mathrm{D}} \operatorname{Ker}(\mathrm{A})$ is defined as:

$$
\lambda^{\mathrm{D}} \operatorname{Ker}(\mathrm{A})=\cap\left\{\mathrm{G} \in \mathrm{SO}_{\lambda^{\mathrm{D}}}(\mathrm{X}): \mathrm{A} \subseteq \mathrm{G}\right\} .
$$

Lemma 1 Let $(\mathrm{X}, \tau)$ be a topological space, $\mathrm{A} \subseteq \mathrm{X}$ and $\lambda: \mathrm{SO}(\mathrm{X}) \rightarrow \mathcal{P}(\mathrm{X})$ be an s-operation. Then $\lambda^{\mathrm{D}} \operatorname{Ker}(A)=\left\{x \in \mathrm{X}: \lambda^{\mathrm{D}} \mathrm{Cl}(\{x\}) \cap A \neq \emptyset\right\}$.

Proof. Let $x \in \lambda^{\mathrm{D}} \operatorname{Ker}(A)$ such that $\lambda^{\mathrm{D}} \operatorname{Cl}(\{x\}) \cap A=\emptyset$. Since $x \notin X \backslash \lambda^{\mathrm{D}} \operatorname{Cl}(\{x\})$ which is a $\lambda^{\mathrm{D}}$-open set containing $A$. Thus $x \notin \lambda^{\mathrm{D}} \operatorname{Ker}(A)$ a contradiction.

Conversely, let $x \in X$ be such that $\lambda^{\mathrm{D}} \operatorname{Cl}(\{x\}) \cap A \neq \emptyset$. If possible, let $x \notin$ $\lambda^{\mathrm{D}} \operatorname{Ker}(A)$. Then there exist a $\lambda^{\mathrm{D}}$-open set $\mathrm{G}$ such that $x \notin \mathrm{G}$ and $A \subseteq \mathrm{G}$. Let $y \in \lambda^{\mathrm{D}} \operatorname{Cl}(\{x\}) \cap A$. This implies that $y \in \lambda^{\mathrm{D}} \operatorname{Cl}(\{x\})$ and $y \in G$, which gives $x \in \mathrm{G}$, a contradiction.

Theorem 1 Let $(\mathrm{X}, \tau)$ be a topological space, $\mathrm{A}$ and $\mathrm{B}$ be subsets of $\mathrm{X}$. Then:

(1) $x \in \lambda^{\mathrm{D}} \operatorname{Ker}(\mathrm{A})$ if and only if $\mathrm{A} \cap \mathrm{F} \neq \emptyset$; for any $\lambda^{\mathrm{D}}$-closed set $\mathrm{F}$ containing $x$.

(2) $\mathrm{A} \subseteq \lambda^{\mathrm{D}} \operatorname{Ker}(\mathrm{A})$ and $\mathrm{A}=\lambda^{\mathrm{D}} \operatorname{Ker}(\mathrm{A})$ if $\mathrm{A}$ is $\lambda^{\mathrm{D}}$-open.

(3) If $\mathrm{A} \subseteq \mathrm{B}$, then $\lambda^{\mathrm{D}} \operatorname{Ker}(\mathrm{A}) \subseteq \lambda^{\mathrm{D}} \operatorname{Ker}(\mathrm{B})$.

Proof. Obvious.

Definition 5 Let $\lambda: S \mathrm{O}(\mathrm{X}) \rightarrow \mathcal{P}(\mathrm{X})$ be an s-operation, a topological space $(\mathrm{X}, \tau)$ is called $\lambda^{\mathrm{D}}-\mathrm{R}_{0}$, if $\mathrm{U} \in \mathrm{SO}_{\lambda^{\mathrm{D}}}(\mathrm{X})$ and $\mathrm{x} \in \mathrm{U}$ then $\lambda^{\mathrm{D}} \mathrm{Cl}(\{x\}) \subseteq \mathrm{U}$.

Example 2 Let $\mathrm{X}=\{\mathrm{a}, \mathrm{b}, \mathrm{c}, \mathrm{d}\}$, and $\tau=\mathcal{P}(\mathrm{X})$. We define an s-operation $\lambda: \mathrm{SO}(\mathrm{X}) \rightarrow \mathcal{P}(\mathrm{X})$ as:

$\lambda(A)=A$, for every subset $A$ of $X$.

$\mathrm{SO}(\mathrm{X})=\mathcal{P}(\mathrm{X})=\mathrm{SO}_{\lambda_{\mathrm{D}}}(\mathrm{X})=\mathrm{SC}_{\lambda^{\mathrm{D}}}(\mathrm{X})$. 
Theorem 2 For any topological space $\mathrm{X}$ and any s-operation $\lambda: \mathrm{SO}(\mathrm{X}) \rightarrow$ $\mathcal{P}(\mathrm{X})$, the following statements are equivalent:

(1) $\mathrm{X}$ is $\lambda^{\mathrm{D}}-\mathrm{R}_{0}$.

(2) $\mathrm{F} \in \mathrm{SC}_{\lambda \mathrm{D}}(\mathrm{X})$ and $\mathrm{x} \notin \mathrm{F}$ implies that $\mathrm{F} \subseteq \mathrm{U}$ and $\mathrm{x} \notin \mathrm{U}$ for some $\mathrm{U} \in$ $\mathrm{SO}_{\lambda \mathrm{D}}(\mathrm{X})$.

(3) $\mathrm{F} \in \mathrm{SC}_{\lambda}(\mathrm{X})$ and $x \notin \mathrm{F}$ implies that $\mathrm{F} \cap \lambda^{\mathrm{D}} \mathrm{Cl}(\{x\}) \neq \emptyset$.

(4) For any two distinct points $x, y$ of $\mathrm{X}$, either $\lambda^{\mathrm{D}} \mathrm{Cl}(\{x\})=\lambda^{\mathrm{D}} \mathrm{Cl}(\{\mathrm{y}\})$ or $\lambda^{\mathrm{D}} \mathrm{Cl}(\{x\}) \cap \lambda^{\mathrm{D}} \mathrm{Cl}(\{y\})=\emptyset$.

\section{Proof.}

$(1) \Rightarrow(2)$ : Let $F \in S C_{\lambda} D(X)$ and $x \notin F$. This implies that $x \in X \backslash F \in$ $\mathrm{SO}_{\lambda \mathrm{D}}(X)$, then $\lambda^{\mathrm{D}} \operatorname{Cl}(\{x\}) \subseteq X \backslash F$ (by (1)). Put $\mathrm{U}=X \backslash \lambda^{\mathrm{D}} \operatorname{Cl}(\{x\})$. Then $x \notin$ $\mathrm{U} \in \mathrm{SO}_{\lambda \mathrm{D}}(\mathrm{X})$ and $\mathrm{F} \subseteq \mathrm{U}$.

$(2) \Rightarrow(3): F \in \mathrm{SC}_{\lambda^{\mathrm{D}}}(\mathrm{X})$ and $\mathrm{x} \notin \mathrm{F}$ then there exists $\mathrm{U} \in \mathrm{SO}_{\lambda^{\mathrm{D}}}(\mathrm{X})$ such that $x \notin \mathrm{U}$ and $\mathrm{F} \subseteq \mathrm{U}($ by $(2))$, then $\mathrm{U} \cap \lambda^{\mathrm{D}} \mathrm{Cl}(\{x\})=\emptyset$ and $\mathrm{F} \cap \lambda^{\mathrm{D}} \mathrm{Cl}(\{x\})=\emptyset$.

$(3) \Rightarrow(4)$ : Suppose that for any two distinct points $x, y$ of $X$, if $\lambda^{\mathrm{D}} \operatorname{Cl}(\{x\}) \neq$ $\lambda^{\mathrm{D}} \mathrm{Cl}(\{y\})$ Then, without loss of generality, we suppose that there exists some $z \in \lambda^{\mathrm{D}} \mathrm{Cl}(\{x\})$ such that $z \notin \lambda^{\mathrm{D}} \mathrm{Cl}(\{y\})$. Thus, there exists a $\lambda^{\mathrm{D}}$-open set $\mathrm{V}$ such that $z \in \mathrm{V}$ and $\mathrm{y} \notin \mathrm{V}$ but $x \in \mathrm{V}$. Thus $x \notin \lambda^{\mathrm{D}} \mathrm{Cl}(\{\mathrm{y}\})$. Hence by (3), $\lambda^{\mathrm{D}} \mathrm{Cl}(\{x\}) \cap \lambda^{\mathrm{D}} \mathrm{Cl}(\{y\})=\emptyset$.

$(4) \Rightarrow(1)$ : Let $\mathrm{U} \in \mathrm{SO}_{\lambda^{\mathrm{D}}}(\mathrm{X})$ and $x \in \mathrm{U}$. Then for each $\mathrm{y} \notin \mathrm{U}, \mathrm{x} \notin \lambda^{\mathrm{D}} \mathrm{Cl}(\{\mathrm{y}\})$. Thus $\lambda^{\mathrm{D}} \operatorname{Cl}(\{x\}) \neq \lambda^{\mathrm{D}} \operatorname{Cl}(\{y\})$. Hence by $(4), \lambda^{\mathrm{D}} \operatorname{Cl}(\{x\}) \cap \lambda^{\mathrm{D}} \operatorname{Cl}(\{y\})=\emptyset$, for each $y \in X \backslash U$. So $\lambda^{\mathrm{D}} \operatorname{Cl}(\{x\}) \cap\left[\cup\left\{\lambda^{\mathrm{D}} \mathrm{Cl}(\{y\}): y \in X \backslash \mathrm{U}\right\}\right]=\emptyset$. Now, $\mathrm{u} \in \mathrm{SO}_{\lambda^{\mathrm{D}}}(\mathrm{X})$ and $y \in X \backslash U$ then $\{y\} \subseteq \lambda^{D} \operatorname{cl}(\{y\}) \subseteq \lambda^{D} \operatorname{cl}(X \backslash U)=X \backslash U$. Thus $X \backslash U=$ $\cup\left\{\lambda^{\mathrm{D}} \mathrm{Cl}(\{y\}): y \in X \backslash \mathrm{U}\right\}$. Hence, $\lambda^{\mathrm{D}} \operatorname{Cl}(\{y\}) \cap X \backslash \mathrm{U}=\emptyset$ then $\lambda^{\mathrm{D}} \operatorname{Cl}(\{x\}) \subseteq \mathrm{U}$. This showing that $(X, \tau)$ is $\lambda^{D}-R_{0}$.

Lemma 2 Let $\lambda: \mathrm{SO}(\mathrm{X}) \rightarrow \mathcal{P}(\mathrm{X})$ be an s-operation. Then $\mathrm{y} \in \lambda^{\mathrm{D}} \operatorname{Ker}(\{x\})$ if and only if $x \in \lambda^{\mathrm{D}} \mathrm{Cl}(\{\mathrm{y}\})$.

Proof. Let $y \notin \lambda^{\mathrm{D}} \operatorname{Ker}(\{x\})$. Then there exists $V \in \mathrm{SO}_{\lambda \mathrm{D}}(X)$ containing $x$ such that $y \notin V$. Therefore $x \notin \lambda^{\mathrm{D}} \operatorname{Cl}(\{y\})$. The converse part can be proved in a similar way.

Theorem 3 Let $\lambda: \mathrm{SO}(\mathrm{X}) \rightarrow \mathcal{P}(\mathrm{X})$ be an s-operation. Then for any two points $x, y$ in $X, \lambda^{\mathrm{D}} \operatorname{Ker}(\{x\}) \neq \lambda^{\mathrm{D}} \operatorname{Ker}(\{y\})$ if and only if $\lambda^{\mathrm{D}} \mathrm{Cl}(\{y\}) \neq \lambda^{\mathrm{D}} \mathrm{Cl}(\{x\})$. 
Proof. Suppose that $\lambda^{\mathrm{D}} \operatorname{Ker}(\{x\}) \neq \lambda^{\mathrm{D}} \operatorname{Ker}(\{y\})$. Then there exists $z \in \lambda^{\mathrm{D}}$ $\operatorname{Ker}(\{x\})$ such that $z \notin \lambda^{\mathrm{D}} \operatorname{Ker}(\{y\})$. Now, $z \in \lambda^{\mathrm{D}} \operatorname{Ker}(x)$ if and only if $x \in$ $\lambda^{\mathrm{D}} \operatorname{Ker}(\{z\})$ by Lemma 2 and $z \notin \lambda^{\mathrm{D}} \operatorname{Ker}(\{y\})$ if and only if $y \in \lambda^{\mathrm{D}} \operatorname{Cl}(\{x\})$ by Lemma 2. Hence $\lambda^{\mathrm{D}} \mathrm{Cl}(\{x\}) \neq \lambda^{\mathrm{D}} \operatorname{Cl}(\{y\})$.

Conversely, suppose that $\lambda^{\mathrm{D}} \mathrm{Cl}(\{x\}) \neq \lambda^{\mathrm{D}} \mathrm{Cl}(\{y\})$. Then there exists $z \in X$ such that $z \in \lambda^{\mathrm{D}} \mathrm{Cl}(\{x\})$ and $z \notin \lambda^{\mathrm{D}} \mathrm{Cl}(\{y\})$ so there exists $\mathrm{U} \in \mathrm{SO}_{\lambda_{\mathrm{D}}}(\mathrm{X})$ such that $z \in \mathrm{U}, \mathrm{y} \notin \mathrm{U}$ and $x \in \mathrm{U}$. Then $\mathrm{y} \notin \lambda^{\mathrm{D}} \operatorname{Ker}(\{x\})$. Thus $\lambda^{\mathrm{D}} \operatorname{Ker}(\{x\}) \neq$ $\lambda^{\mathrm{D}} \operatorname{Ker}(\{y\})$.

Theorem 4 Let $\lambda: \mathrm{SO}(\mathrm{X}) \rightarrow \mathcal{P}(\mathrm{X})$ be an s-operation. Then $(\mathrm{X}, \tau)$ is $\lambda^{\mathrm{D}}-\mathrm{R}_{0}$ if and only if for any two points $x, y \in X, \lambda^{\mathrm{D}} \operatorname{Ker}(\{x\}) \notin \lambda^{\mathrm{D}} \operatorname{Ker}(\{y\})$, implies that $\lambda^{\mathrm{D}} \operatorname{Ker}(\{x\}) \cap \lambda^{\mathrm{D}} \operatorname{Ker}(\{y\})=\emptyset$.

Proof. Let $x, y$ be any two points in a $\lambda^{\mathrm{D}}-\mathrm{R}_{0}$ space $X$ such that $\lambda^{\mathrm{D}} \operatorname{Ker}(\{x\}) \neq$ $\lambda^{\mathrm{D}} \operatorname{Ker}(\{y\})$. Hence by Theorem 3, $\lambda^{\mathrm{D}} \mathrm{Cl}(\{x\}) \neq \lambda^{\mathrm{D}} \mathrm{Cl}(\{y\})$. We show that $\lambda^{\mathrm{D}} \operatorname{Ker}(\{x\}) \cap \lambda^{\mathrm{D}} \operatorname{Ker}(\{y\})=\emptyset$. In fact, if $z \in \lambda^{\mathrm{D}} \operatorname{Ker}(\{x\}) \cap \lambda^{\mathrm{D}} \operatorname{Ker}(\{y\})$, then by Lemma 2, we have $x, y \in \lambda^{\mathrm{D}} \mathrm{Cl}(z)$ and by Theorem 2 , we obtain that $\lambda^{\mathrm{D}} \mathrm{Cl}(\{x\})=\lambda^{\mathrm{D}} \mathrm{Cl}(\{z\})=\lambda^{\mathrm{D}} \mathrm{Cl}(\{y\})$ which is impossible.

Conversely, suppose that for any points $x, y \in X, \lambda^{D} \operatorname{Ker}(\{x\}) \neq \lambda^{D} \operatorname{Ker}(\{y\})$. Thus $\lambda^{\mathrm{D}} \operatorname{Ker}(\{x\}) \cap \lambda^{\mathrm{D}} \operatorname{Ker}(\{y\})=\emptyset$. Hence we get $\lambda^{\mathrm{D}} \operatorname{Cl}(\{x\}) \cap \lambda^{\mathrm{D}} \operatorname{Cl}(\{y\})=\emptyset$. In fact $z \in \lambda^{\mathrm{D}} \operatorname{Cl}(\{x\}) \cap \lambda^{\mathrm{D}} \mathrm{Cl}(\{y\})$, this implies that $x, y \in \lambda^{\mathrm{D}} \operatorname{Ker}(\{z\})$. Thus $\lambda^{\mathrm{D}} \operatorname{Cl}(\{x\}) \cap \lambda^{\mathrm{D}} \operatorname{Cl}(\{z\}) \neq \emptyset$. Hence by hypothesis, we get $\lambda^{\mathrm{D}} \operatorname{Ker}(\{x\})=$ $\lambda^{\mathrm{D}} \operatorname{Ker}(\{z\})$. By similar way it follows that $\lambda^{\mathrm{D}} \operatorname{Ker}(\{x\})=\lambda^{\mathrm{D}} \operatorname{Ker}(\{z\})$. Thus $\lambda^{\mathrm{D}} \operatorname{Ker}(\{x\}) \neq \lambda^{\mathrm{D}} \operatorname{Ker}(\{y\})$ which is a contradiction. Hence $\lambda^{\mathrm{D}} \operatorname{Cl}(\{x\}) \cap \lambda^{\mathrm{D}} \operatorname{Cl}(\{y\})$ $\neq \emptyset$ and then by Theorem 2 , the space $X$ is $\lambda^{D}-R_{0}$.

Theorem 5 Let $(X, \tau)$ be a topological space and for any s-operation $\lambda$ : $\mathrm{SO}(\mathrm{X}) \rightarrow \mathcal{P}(\mathrm{X})$ the following statements are equivalent:

(1) $\mathrm{X}$ is a $\lambda^{\mathrm{D}}-\mathrm{R}_{0}$ space.

(2) For any non-empty set $\mathrm{A}$ in $\mathrm{X}$ and any $\mathrm{G} \in \mathrm{SO}_{\lambda^{\mathrm{D}}}(\mathrm{X})$ such that $\mathrm{A} \cap \mathrm{G} \neq \emptyset$ there exists $\mathrm{F} \in \mathrm{SC}_{\lambda^{\mathrm{D}}}(\mathrm{X})$ such that $\mathrm{A} \cap \mathrm{F} \neq \emptyset$ and $\mathrm{F} \subseteq \mathrm{G}$.

(3) For any $\mathrm{G} \in \mathrm{SO}_{\lambda^{\mathrm{D}}}(\mathrm{X}), \mathrm{G}=\cup\left\{\mathrm{F} \in \mathrm{SC}_{\lambda \mathrm{D}}(\mathrm{X}): \mathrm{F} \subseteq \mathrm{G}\right\}$.

(4) For any $\mathrm{F} \in \mathrm{SC}_{\lambda^{\mathrm{D}}}(\mathrm{X}), \mathrm{F}=\cap\left\{\mathrm{G} \in \mathrm{SO}_{\lambda^{\mathrm{D}}}(\mathrm{X}): \mathrm{F} \subseteq \mathrm{G}\right\}$.

(5) For any $x \in X, \lambda^{\mathrm{D}} \mathrm{Cl}(\{x\}) \subseteq \lambda^{\mathrm{D}} \operatorname{Ker}(\{x\})$. 


\section{Proof.}

$(1) \Rightarrow(2)$ : Let $A$ be a non-empty subset of $X$ and $G \in \mathrm{SO}_{\lambda^{D}}(X)$ such that $A \cap G \neq \emptyset$. Let $x \in A \cap G$. Then as $x \in G \in S O_{\lambda^{D}}(X)$, by (1), we get $\lambda^{\mathrm{D}} \mathrm{Cl}(\{x\}) \subseteq \mathrm{G}$. Put $\mathrm{F}=\lambda^{\mathrm{D}} \mathrm{Cl}(\{x\})$. Then $\mathrm{F} \in \mathrm{SC}_{\lambda^{\mathrm{D}}}(\mathrm{X}), \mathrm{F} \subseteq \mathrm{G}$ and $\mathrm{A} \cap \mathrm{F} \neq \emptyset$.

$(2) \Rightarrow(3)$ : Let $\mathrm{G} \in \mathrm{SO}_{\lambda^{\mathrm{D}}}(\mathrm{X})$. Then $\bigcup\left\{\mathrm{F} \in \mathrm{SC}_{\lambda^{\mathrm{D}}}(\mathrm{X}): \mathrm{F} \subseteq \mathrm{G}\right\} \subseteq \mathrm{G}$. Let $x \in \mathrm{G}$. Then there exists $\mathrm{F} \in \mathrm{SC}_{\lambda_{\mathrm{D}}}(\mathrm{X})$ such that $\mathrm{x} \in \mathrm{F}$ and $\mathrm{F} \subseteq \mathrm{G}$. Thus $x \in \mathrm{F} \cup\left\{\mathrm{K} \in \mathrm{SC}_{\lambda \mathrm{D}}(\mathrm{X}): \mathrm{K} \subseteq \mathrm{G}\right\}$. Hence (3) follows.

$(3) \Rightarrow(4)$ : Straight forward.

$(4) \Rightarrow(5)$ : Let $x \in X$. Now, $y \notin \lambda^{\mathrm{D}} \operatorname{Ker}(\{x\})$ implies there exists $V \in \mathrm{SO}_{\lambda^{\mathrm{D}}}(\mathrm{X})$ such that $x \in V$ and $y \notin V$ then $\lambda^{\mathrm{D}} \operatorname{Cl}(\{y\}) \cap \mathrm{V}=\emptyset$. This implies by (4) $\left[\cap\left\{G \in \mathrm{SO}_{\lambda^{\mathrm{D}}}(X): \lambda^{\mathrm{D}} \mathrm{Cl}(\{\mathrm{y}\}) \subseteq \mathrm{G}\right\}\right] \cap \mathrm{V}=\emptyset$. Then there exists $\mathrm{G} \in \mathrm{SO}_{\lambda_{\mathrm{D}}}(\mathrm{X})$ such that $x \in \mathrm{G}$ and $\lambda^{\mathrm{D}} \mathrm{Cl}(\{y\}) \subseteq \mathrm{G}$, so $y \notin \lambda^{\mathrm{D}} \mathrm{Cl}(\{x\})$.

$(5) \Rightarrow(1)$ : Let $G \in \mathrm{SO}_{\lambda^{\mathrm{D}}}(\mathrm{X})$ and $x \in \mathrm{G}$. Let $\mathrm{y} \in \lambda^{\mathrm{D}} \operatorname{Ker}(\{x\})$. Then $x \in$ $\lambda^{\mathrm{D}} \mathrm{Cl}(\{y\})$ and hence $y \in \mathrm{G}$. This implies that $\lambda^{\mathrm{D}} \operatorname{Ker}(\{x\}) \subseteq \mathrm{G}$. Thus $x \in$ $\lambda^{\mathrm{D}} \operatorname{Cl}(\{x\}) \subseteq \lambda^{\mathrm{D}} \operatorname{Ker}(\{x\}) \subseteq \mathrm{G}$. Hence $\mathrm{X}$ is $\lambda^{\mathrm{D}}-\mathrm{R}_{0}$.

Corollary 1 Let $\lambda: \mathrm{SO}(\mathrm{X}) \rightarrow \mathcal{P}(\mathrm{X})$ be an s-operation. Then $\mathrm{X}$ is $\lambda^{\mathrm{D}}-\mathrm{R}_{0}$ if and only if $\lambda^{\mathrm{D}} \mathrm{Cl}(\{x\})=\lambda^{\mathrm{D}} \operatorname{Ker}(\{x\})$, for all $\mathrm{x} \in \mathrm{X}$.

Proof. Suppose that $X$ is $\lambda^{D}-R_{0}$. By Theorem $5, \lambda^{D} \operatorname{Cl}(\{x\}) \subseteq \lambda^{D} \operatorname{Ker}(\{x\})$. For each $x \in X$. Let $y \in \lambda^{\mathrm{D}} \operatorname{Ker}(\{x\})$. Then $x \in \lambda^{\mathrm{D}} \operatorname{Cl}(\{y\})$ (by Lemma 2), and hence by Theorem 2, $\lambda^{\mathrm{D}} \operatorname{Cl}(\{x\})=\lambda^{\mathrm{D}} \operatorname{Cl}(\{y\})$. Thus $y \in \lambda^{\mathrm{D}} \mathrm{Cl}(\{x\})$ and hence $\lambda^{\mathrm{D}} \operatorname{Ker}(\{x\}) \subseteq \lambda^{\mathrm{D}} \operatorname{Cl}(\{x\})$. Thus $\lambda^{\mathrm{D}} \operatorname{Cl}(\{x\})=\lambda^{\mathrm{D}} \operatorname{Ker}(\{x\})$.

The converse is obvious in view of Theorem 5 .

Theorem 6 Let $(\mathrm{X}, \tau)$ be a topological space and $\lambda: \mathrm{SO}(\mathrm{X}) \rightarrow \mathcal{P}(\mathrm{X})$ be an s-operation. A space $\mathrm{X}$ is $\lambda^{\mathrm{D}}-\mathrm{R}_{0}$ if and only if for any $\mathrm{X}, \mathrm{y} \in \mathrm{X}$, whenever $x \in \lambda^{\mathrm{D}} \mathrm{Cl}(\{\mathrm{y}\})$ implies $\mathrm{y} \in \lambda^{\mathrm{D}} \mathrm{Cl}(\{\mathrm{x}\})$ and conversely.

Proof. Suppose that a topological space $(X, \tau)$ is $\lambda^{D}-R_{0}$. Let $x \in \lambda^{D} \operatorname{Cl}(\{y\})$. Then by Theorem 5 , we have $\lambda^{\mathrm{D}} \operatorname{Cl}(\{y\}) \subseteq \lambda^{\mathrm{D}} \operatorname{Ker}(\{x\})$. Thus $x \in \lambda^{\mathrm{D}} \operatorname{Ker}(\{y\})$. Hence by Lemma 1, we have $y \in \lambda^{\mathrm{D}} \mathrm{Cl}(\{x\})$.

Conversely, let $\mathrm{U} \in \mathrm{SO}_{\lambda^{\mathrm{D}}}(\mathrm{X})$ and $\mathrm{x} \in \mathrm{U}$. Let $\mathrm{y} \in \lambda^{\mathrm{D}} \mathrm{Cl}(\{x\})$ hence by hypothesis, $x \in \lambda^{\mathrm{D}} \operatorname{Cl}(\{y\})$. Since $x \in \mathrm{U}$, so $y \in U$. Hence $\lambda^{\mathrm{D}} \mathrm{Cl}(\{x\}) \subseteq \mathrm{U}$. Thus $X$ is $\lambda^{D}-R_{0}$.

Theorem 7 Let $\mathrm{X}$ be a topological space and $\lambda: \mathrm{SO}(\mathrm{X}) \rightarrow \mathcal{P}(\mathrm{X})$ be an $s$ operation. Then the following statements are equivalent:

(1) $\mathrm{X}$ is $\lambda^{\mathrm{D}}-\mathrm{R}_{0}$. 
(2) If $\mathrm{F} \in \mathrm{SC}_{\lambda^{\mathrm{D}}}(\mathrm{X})$ then $\mathrm{F}=\lambda^{\mathrm{D}} \operatorname{Ker}(\mathrm{F})$.

(3) If $\mathrm{F} \in \mathrm{SC}_{\lambda^{\mathrm{D}}}(\mathrm{X})$ and $\mathrm{x} \in \mathrm{F}$, then $\lambda^{\mathrm{D}} \operatorname{Ker}(\{\mathrm{x}\}) \subseteq \mathrm{F}$.

(4) If $x \in X$, then $\lambda^{\mathrm{D}} \operatorname{Ker}(\{x\}) \subseteq \lambda^{\mathrm{D}} \operatorname{Cl}(\{x\})$.

\section{Proof.}

$(1) \Rightarrow(2)$ : Follows from Theorem 5 .

$(2) \Rightarrow(3)$ : Follows from the fact that $x \in F$ then $\lambda^{\mathrm{D}} \operatorname{Ker}(\{x\}) \subseteq \lambda^{\mathrm{D}} \operatorname{Ker}(\mathrm{F})=\mathrm{F}$ by part 3 of Theorem 1 .

$(3) \Rightarrow(4)$ : Since $x \in \lambda^{\mathrm{D}} \mathrm{Cl}(\{x\}) \in \mathrm{SC}_{\lambda \mathrm{D}}(\mathrm{X})$ we have by $(3), \lambda^{\mathrm{D}} \operatorname{Ker}(\{x\}) \subseteq$ $\lambda^{\mathrm{D}} \mathrm{Cl}(\{x\})$ and $(4)$ follows.

(4) $\Rightarrow(1)$ : Let $\mathrm{U} \in \mathrm{SO}_{\lambda^{\mathrm{D}}}(\mathrm{X})$ and $x \in \mathrm{U}$. To show $\lambda^{\mathrm{D}} \mathrm{Cl}(\{x\}) \subseteq \mathrm{U}$. If possible, suppose that, there exists $y \in \lambda^{\mathrm{D}} \operatorname{Cl}(\{x\})$ such that $\mathrm{y} \notin \mathrm{U}$. Then $\mathrm{y} \in X \backslash \mathrm{U}$. This by (4) implies that $\lambda^{\mathrm{D}} \operatorname{Ker}(\{y\}) \subseteq X \backslash \mathrm{U}$. Therefore $\mathrm{U} \subseteq X \backslash \lambda^{\mathrm{D}} \operatorname{Ker}(\{x\})$. So $x \notin \lambda^{\mathrm{D}} \operatorname{Ker}(\{y\})$. Then, there exists a $\lambda^{\mathrm{D}}$-open set $\mathrm{G}$ such that $\mathrm{y} \in \mathrm{G}$ but $x \notin \mathrm{G}$. This implies that $\mathrm{y} \notin \lambda^{\mathrm{D}} \mathrm{Cl}(\{x\})$ which is impossible. Hence $\lambda^{\mathrm{D}} \mathrm{Cl}(\{x\}) \sqsubseteq \mathrm{U}$. Thus $X$ is a $\lambda^{\mathrm{D}}-\mathrm{R}_{0}$ space.

Definition 6 Let $(X, \tau)$ be a topological space and $\lambda: S \mathrm{O}(\mathrm{X}) \rightarrow \mathcal{P}(\mathrm{X})$ be an s-operation. The space $\mathrm{X}$ is said to be $\lambda^{\mathrm{D}}-\mathrm{R}_{1}$ if for $\mathrm{x}, \mathrm{y} \in \mathrm{X}$ with $\lambda^{\mathrm{D}} \mathrm{Cl}(\{\mathrm{x}\}) \neq$ $\lambda^{\mathrm{D}} \mathrm{Cl}(\mathrm{y})$ there exist disjoint $\lambda^{\mathrm{D}}$-open sets $\mathrm{U}$ and $\mathrm{V}$ such that $\lambda^{\mathrm{D}} \mathrm{Cl}(\{\mathrm{x}\}) \subseteq \mathrm{U}$ and $\lambda^{\mathrm{D}} \mathrm{Cl}(\{\mathrm{y}\}) \subseteq \mathrm{V}$.

Remark 1 A space $\mathrm{X}$ in Example 2 is $\lambda^{\mathrm{D}}-\mathrm{R}_{1}$.

Theorem 8 Every $\lambda^{\mathrm{D}}-\mathrm{R}_{1}$ space is a $\lambda^{\mathrm{D}}-\mathrm{R}_{0}$ space.

Proof. Let $\mathrm{U} \in \mathrm{SO}_{\lambda^{\mathrm{D}}}(\mathrm{X})$ and $x \in \mathrm{U}$. If $\mathrm{y} \notin \mathrm{U}$ then $\lambda^{\mathrm{D}} \mathrm{Cl}(\{x\}) \neq \lambda^{\mathrm{D}} \mathrm{Cl}(\{\mathrm{y}\})$ (as $\left.x \notin \lambda^{\mathrm{D}} \mathrm{Cl}(\{y\})\right)$. Hence there exists $\mathrm{V} \in \mathrm{SO}_{\lambda^{\mathrm{D}}}(\mathrm{X})$ such that $\lambda^{\mathrm{D}} \mathrm{Cl}(\{\mathrm{y}\}) \subseteq \mathrm{V}$ and $x \notin \mathrm{V}$. This gives $\mathrm{y} \notin \lambda^{\mathrm{D}} \mathrm{Cl}(\{\mathrm{y}\})$, proving that $\lambda^{\mathrm{D}} \mathrm{Cl}(\{x\}) \subseteq \mathrm{U}$. So $\mathrm{X}$ is a $\lambda^{\mathrm{D}}-\mathrm{R}_{0}$ space.

The converse of Theorem 8 is not true, we can show it by the following example:

Example 3 Let $\mathrm{X}=\{\mathrm{a}, \mathrm{b}, \mathrm{c}, \mathrm{d}\}$, and $\tau=\mathcal{P}(\mathrm{X})$. We define an s-operation $\lambda: \mathrm{SO}(\mathrm{X}) \rightarrow \mathcal{P}(\mathrm{X})$ as:

$$
\lambda(A)= \begin{cases}X & \text { Otherwise } \\ A & \text { if } A=\emptyset \text { or }\{b, c\} \text { or }\{a, c\} \text { or }\{a, b\} .\end{cases}
$$


Now:

$\mathrm{SO}(\mathrm{X})=\mathcal{P}(\mathrm{X})$.

$\mathrm{SO}_{\lambda \mathrm{D}}(X)=\{\emptyset,\{b, c\},\{a, c\},\{a, b\}, X\}$.

$\mathrm{SC}_{\lambda \mathrm{D}}(\mathrm{X})=\{\emptyset,\{\mathrm{a}\},\{\mathrm{b}\},\{\mathrm{c}\}, X\}$.

Clearly $\mathrm{X}$ is $\lambda^{\mathrm{D}}-\mathrm{R}_{0}$ but it is not $\lambda^{\mathrm{D}}-\mathrm{R}_{1}$.

Theorem 9 Let $(\mathrm{X}, \tau)$ be a topological space and $\lambda: \mathrm{SO}(\mathrm{X}) \rightarrow \mathcal{P}(\mathrm{X})$ be an s-operation. Then the following statements are equivalent:

(1) $\mathrm{X}$ is $\lambda^{\mathrm{D}}-\mathrm{R}_{1}$.

(2) For any $\mathrm{x}, \mathrm{y} \in \mathrm{X}$, one of the following holds:

a) For $\mathrm{U} \in \mathrm{SO}_{\lambda}(\mathrm{X}), \mathrm{x} \in \mathrm{U}$ if and only if $\mathrm{y} \in \mathrm{U}$;

b) There exist disjoint $\lambda^{\mathrm{D}}$-open sets $\mathrm{U}$ and $\mathrm{V}$ such that $\mathrm{x} \in \mathrm{U}, \mathrm{y} \in \mathrm{V}$.

(3) If $x, y \in X$, such that $\lambda^{\mathrm{D}} \mathrm{Cl}(\{x\}) \neq \lambda^{\mathrm{D}} \mathrm{Cl}(\{\mathrm{y}\})$ then there exist $\lambda^{\mathrm{D}}$-closed sets $\mathrm{F}$ and $\mathrm{H}$ such that $\mathrm{x} \in \mathrm{F}, \mathrm{y} \notin \mathrm{F}, \mathrm{y} \in \mathrm{H}, \mathrm{x} \notin \mathrm{H}$ and $\mathrm{X}=\mathrm{F} \cup \mathrm{H}$.

\section{Proof.}

$(1) \Rightarrow(2):$ Let $x, y \in X$. Then $\lambda^{\mathrm{D}} \operatorname{Cl}(\{x\})=\lambda^{\mathrm{D}} \mathrm{Cl}(\{y\})$ or $\lambda^{\mathrm{D}} \mathrm{Cl}(\{x\}) \neq$ $\lambda^{\mathrm{D}} \mathrm{Cl}(\{y\})$. If $\lambda^{\mathrm{D}} \mathrm{Cl}(\{x\})=\lambda^{\mathrm{D}} \mathrm{Cl}(\{y\})$ and $\mathrm{U} \in \mathrm{SO}_{\lambda^{\mathrm{D}}}(\mathrm{X})$, then for any $\mathrm{U} \in$ $\mathrm{SO}_{\lambda^{\mathrm{D}}}(\mathrm{X}), x \in \mathrm{U}$ then $\mathrm{y} \in \lambda^{\mathrm{D}} \mathrm{Cl}(\{x\})=\lambda^{\mathrm{D}} \mathrm{Cl}(\{\mathrm{y}\}) \subseteq \mathrm{U}$ then (as $\mathrm{X}$ is $\lambda^{\mathrm{D}}-\mathrm{R}_{0}$ ). If $\lambda^{\mathrm{D}} \mathrm{Cl}(\{x\}) \neq \lambda^{\mathrm{D}} \mathrm{Cl}(\{\mathrm{y}\})$, then there exist $\mathrm{U}, \mathrm{V} \in \mathrm{SO}_{\lambda^{\mathrm{D}}}(\mathrm{X})$ such that $x \in$ $\lambda^{\mathrm{D}} \mathrm{Cl}(\{x\}) \subseteq \mathrm{U}, \mathrm{y} \in \lambda^{\mathrm{D}} \mathrm{Cl}(\{\mathrm{y}\}) \subseteq \mathrm{V}$ and $\mathrm{U} \cap \mathrm{V}=\emptyset$.

$(2) \Rightarrow(3)$ : Let $x, y \in X$ such that $\lambda^{\mathrm{D}} \operatorname{Cl}(\{x\}) \neq \lambda^{\mathrm{D}} \operatorname{Cl}(\{y\})$. Then $x \notin \lambda^{\mathrm{D}} \operatorname{Cl}(\{y\})$, so that there exists $G \in S_{\lambda^{D}}(X)$, such that $x \in G$ and $y \notin G$. Thus by (2), there exist disjoint $\lambda^{\mathrm{D}}$-open sets $\mathrm{U}$ and $\mathrm{V}$ such that $x \in \mathrm{U}, \mathrm{y} \in \mathrm{V}$. Put $\mathrm{F}=\mathrm{X} \backslash \mathrm{V}$ and $\mathrm{H}=X \backslash U$. Then $F, H \in S O_{\lambda D}(X), x \in F, y \notin F, y \in H, x \notin H$ and $X=F \cup H$.

$(3) \Rightarrow(1)$ : Let $\mathrm{U} \in \mathrm{SO}_{\lambda}(\mathrm{X})$ and $x \in \mathrm{U}$. Then $\lambda^{\mathrm{D}} \mathrm{Cl}(\{x\}) \subseteq \mathrm{U}$. In fact, otherwise there exists $y \in \lambda^{\mathrm{D}} \mathrm{Cl}(\{x\}) \cap X \backslash U$. Implies that $\lambda^{\mathrm{D}} \mathrm{Cl}(\{x\}) \neq \lambda^{\mathrm{D}} \mathrm{Cl}(\{y\})$ as $\left.x \notin \lambda^{\mathrm{D}} \mathrm{Cl}(\{\boldsymbol{y}\})\right)$ and so by (3), there exist $\mathrm{F}, \mathrm{H} \in \mathrm{SO}_{\lambda^{\mathrm{D}}}(\mathrm{X})$ such that $\mathrm{x} \in \mathrm{F}$, $y \notin F, y \in H, x \notin H$ and $X=F \cup H$. Then $y \in H \backslash F=X \backslash F$ and $x \notin X \backslash F$, where $X \backslash F \in S_{\lambda^{D}}(X)$, which is a contradiction to the fact that $y \in \lambda^{\mathrm{D}} \mathrm{Cl}(\{x\})$. Hence $\lambda^{\mathrm{D}} \operatorname{Cl}(\{x\}) \subseteq \mathrm{U}$. Thus $\mathrm{X}$ is $\lambda^{\mathrm{D}}-\mathrm{R}_{0}$. To show $\mathrm{X}$ to be $\lambda^{\mathrm{D}}-\mathrm{R}_{1}$. Assume that $a, b \in X$ with $\lambda^{D} \operatorname{Cl}(\{a\}) \neq \lambda^{D} \operatorname{Cl}(\{b\})$. Then as above, there exist $K, L \in S C_{\lambda D}(X)$ such that $a \in K, b \notin K, b \in L, a \notin L$ and $X=K \cup L$. Thus $a \in K \backslash L \in S O_{\lambda^{D}}(X), b \in L \backslash K \in S_{\lambda^{D}}(X)$. So $\lambda^{D} \operatorname{Cl}(\{a\}) \subseteq K \backslash L$, $\lambda^{\mathrm{D}} \mathrm{Cl}(\{\mathrm{b}\}) \subseteq \mathrm{L} \backslash K$. Thus $\mathrm{X}$ is $\lambda^{\mathrm{D}}-\mathrm{R}_{1}$. 
Proposition 2 Let $(X, \tau)$ be a topological space and $\lambda: S \mathrm{O}(\mathrm{X}) \rightarrow \mathcal{P}(\mathrm{X})$ be an s-operation. Then $\mathrm{X}$ is $\lambda^{\mathrm{D}}-\mathrm{R}_{1}$, if and only if for $\mathrm{x}, \mathrm{y} \in \mathrm{X}$, with $\lambda^{\mathrm{D}} \operatorname{Ker}(\{\mathrm{x}\}) \neq$ $\lambda^{\mathrm{D}} \operatorname{Ker}(\{\mathrm{y}\})$ there exist disjoint $\lambda^{\mathrm{D}}$-open sets $\mathrm{U}$ and $\mathrm{V}$ such that $\lambda^{\mathrm{D}} \mathrm{Cl}(\{\mathrm{x}\}) \subseteq \mathrm{U}$ and $\lambda^{\mathrm{D}} \mathrm{Cl}(\{\mathrm{y}\}) \subseteq \mathrm{V}$.

Proof. Follows from Theorem 3 and Definition 6.

\section{Conclusion}

Introduced by Alais B. Khalaf and Sarhad F. Namiq [1]. The main results are the following:

(1) Let $(X, \tau)$ be a topological space, and $\lambda: S O(X) \rightarrow \mathcal{P}(X)$ be an soperation and $A \subseteq X$. Then $\lambda^{\mathrm{D}} \operatorname{Ker}(\{A\})=\left\{x \in X: \lambda^{\mathrm{D}} \operatorname{Cl}(\{x\}) \cap A \neq \emptyset\right\}$.

(2) For any topological space $X$ and any s-operation $\lambda: S O(X) \rightarrow \mathcal{P}(X)$, the following statements are equivalent:

a) $X$ is $\lambda^{D}-R_{0}$.

b) $\mathrm{F} \in \mathrm{SC}_{\lambda_{\mathrm{D}}}(\mathrm{X})$ and $\mathrm{x} \in \mathrm{F}$ implies that $\mathrm{F} \subseteq \mathrm{U}$ and $\mathrm{x} \in \mathrm{U}$ for some $\mathrm{U} \in \mathrm{SO}_{\lambda_{\mathrm{D}}}(\mathrm{X})$.

c) $\mathrm{F} \in \mathrm{SC}_{\lambda^{\mathrm{D}}}(\mathrm{X})$ and $x \notin \mathrm{F}$ implies that $\lambda^{\mathrm{D}} \mathrm{Cl}(\{x\}) \cap \lambda^{\mathrm{D}} \mathrm{Cl}(\{\mathrm{y}\})=\emptyset$.

d) For any two distinct points $x, y$ of $X$, either $\lambda^{\mathrm{D}} \mathrm{Cl}(\{x\})=\lambda^{\mathrm{D}} \mathrm{Cl}(\{y\})$ or $\lambda^{\mathrm{D}} \operatorname{Cl}(\{x\}) \cap \lambda^{\mathrm{D}} \operatorname{Cl}(\{y\})=\emptyset$.

(3) Every $\lambda^{\mathrm{D}}-\mathrm{R}_{1}$ space is a $\lambda^{\mathrm{D}}-\mathrm{R}_{0}$ space.

\section{References}

[1] Alias B. Khalaf and Sarhad F. Namiq, New types of continuity and separation axiom based operation in topological spaces, M. Sc. Thesis, University of Sulaimani (2011).

[2] Alias B. Khalaf, Sarhad F. Namiq, Generalized $\lambda$-Closed Sets and $(\lambda, \gamma)^{\mathrm{D}}$-Continuous Functions, International Journal of Scientific \& Engineering Research, Volume 3, Issue 12, December-2012 1 ISSN 2229-5518.

[3] A. S. Davis, Indexed systems of neighborhoods for general topologi-cal spaces, Amer. Math. Monthly, 68 (1961), 886-893. 
[4] N. Levine, Semi-open sets and semi-continuity in topological spaces, Amer. Math. Monthly, 70 (1) (1963), 36-41.

[5] Sarhad F. Namiq, Some Properties of $\lambda^{\mathrm{D}}$-Open Sets in Topological Spaces (submit).

[6] N. A. Shanin, On separation in topological spaces, Dokl. Akad. Nauk. SSSR, 38 (1943), 110-113.

[7] J. N. Sharma and J. P. Chauhan, Topology (General and Algebraic), Krishna Prakashna Media, India. (2011).

Received: January 23, 2020 